\section{Antioxidant activity and storage regime of defatted grape seeds flour}

\author{
Adelina L. Bogoeva, ${ }^{1}$ \\ Albena G. Durakova, ${ }^{1}$ \\ Atanas I. Pavlov, ${ }^{2}$ \\ Velichka B. Yanakieva, ${ }^{3}$ \\ Radka Z. Vrancheva, ${ }^{2}$ \\ Bozhidar V. Bozadzhiev, ${ }^{4}$
}

Kornelia B. Choroleeva ${ }^{5}$

${ }^{1}$ Department of Process Engineering;

${ }^{2}$ Department of Analytical Chemistry;

${ }^{3}$ Department of Microbiology;

${ }^{4}$ Department of Technology of Grain,

Fodder, Bread and Confectionery

Products; ${ }^{5}$ Language Training Centre,

University of Food Technologies,

Plovdiv, Bulgaria

\begin{abstract}
In the present paper, we examined the antioxidant activity of a defatted grape seeds flour of different grape varieties locally grown in Bulgaria. The seeds are retrieved after alcoholic fermentation and the antioxidant activity of the flour was assessed by using four different methods, namely DPPH, ABTS, FRAP and CUPRAC. The results are presented in $\mathrm{mM} \mathrm{TE} / \mathrm{g}$ extract. The values are 586,08 $( \pm 41,55)$; 945,41 $( \pm 90,97) ; 553,39( \pm 45,57)$ and 667,73 $( \pm 64,30)$, respectively. The results are also showed in $\mathrm{mM} \mathrm{TE} / \mathrm{g}$ flour. The values are $58,67( \pm 4,16) ; 94,64( \pm 9,11) ; 55,40( \pm 4,56)$ and $66,85( \pm 6,44)$, respectively. During three-month storage of the flour in plastic bags (temperature $25^{\circ} \mathrm{C}$ and relative humidity $75 \%$ ), no living cells of pathogenic organisms (Escherichia coli, Staphylococcus aureus and Salmonella spp.) or apparent molding were detected. The flour particle size has not changed either.
\end{abstract}

\section{Introduction}

Consumers have increasingly become aware of eating healthy and maintaining good health. In order to satisfy their needs, it is extremely important for food producers to develop and produce foods containing a wide range of biologically active substances with disease-preventing and prophylactic effect. ${ }^{1-3}$ The interest in antioxidants has been constantly growing. ${ }^{4,5}$ Antioxidants are low molecular weight substances, which prevent the oxidation of other chemical agents, absorbing to some extent the ionizing radiation from the environment and toxic pollutants. In biological systems, metabolic processes take place all the time, which results in the release of free radicals. These are highly chemically reactive particles, which oxidize various biomolecules, such as enzymes, proteins, DNA and lipids. This may lead to a number of serious diseases in humans, for instance, cancer, down syndrome, arthritis, atherosclerosis, neurodegenerative disorders, cardio-vascular disease, etc. ${ }^{6}$ Antioxidants have the ability to capture free radicals before to influence on human health. According to Henning et al., ${ }^{7}$ the consumption of fruits and vegetables high in antioxidants was prevention of the effect of free radicals.

Grapes and grape seeds are very rich in substances characterized by antioxidant activity: resveratrol, catechin, epicatechin, gallic acid, quercetin, rutin, antocyanidins, etc. ${ }^{8,9}$ A number of studies prove the health effects of grapes for the heart, kidneys, liver, and stomach and especially their role in neutralizing free radicals which degenerate human health. ${ }^{10,11}$ Grapes contain calcium, magnesium, sodium, iron, aluminium, manganese, sulphur, phosphorus, copper, iodine, bromine, zinc, and silicon. ${ }^{12}$

In the past, the French used grape seeds to cure scurvy, thrombophlebitis, and injuries, which were difficult to treat. ${ }^{13}$ This has made the current French nutritionists to become among the leading scientists in the world to study grapes and their products.

In contemporary times, grape seeds flour is gaining ground in the food industry as an ingredient in the manufacture of various food products. ${ }^{14-16}$ Grape seeds flour is gluten-free and can be included as a biologically active substance in foods consumed by people who suffer from coeliac. ${ }^{17}$

The literature review provided the results for the antioxidant activity of grape seeds flour but the data published was not uniform. . $^{2,10,18}$ There is no data on postfermentation grape seeds flour produced from different grape varieties locally grown in Bulgaria. The literature also gives no information on the storage of postfermentation grape seeds flour from Bulgarian grape cultivars. The conditions and length of storage of foods are very important in the preservation of their nutritive value and health effects. That is why we analyzed in detail the antioxidant activity and storage of defatted flour from post-fermentation grape seeds belonging to Bulgarian grape cultivars. The present study aims at determining the antioxidant activity and storage regimes of defatted flour from grape seeds (a post-fermentation by-product in wine production).
Correspondence: Albena Georgieva Durakova, Department of Process Engineering in University of Food Technologies (UFT), 26 Maritsa Blvd, 4000 Plovdiv, Bulgaria.

Tel.: 00359.895.607.427

E-mail: aldurakova@abv.bg

Key words: grape, grape seeds flour, antioxidants, bioactive compounds, by-product.

Contributions: the authors contributed equally. Conflict of interests: the authors declare no potential conflict of interests.

Acknowledgments: This study was conducted with the kind support of the UNESCO Chair Culture \& Traditions of Wines at Institute of Vine and Wine (IUVV - Institut Jules Guyot), University of Burgundy, Dijon, France.

Fundings: Scholarship support for young researchers - Adelina Bogoeva (from December 2016-April 2017) in the programme of the UNESCO Chair Culture \& Traditions of Wines at Institute of Vine and Wine (IUVV - Institut Jules Guyot), University of Burgundy, Dijon, France.

Conference presentation: part of this paper was presented at the Fourth Edition of the International Conference Series on Wine Active Compounds (WAC 2017) - 29, 30, 31 March 2017, Beaune, France.

Received for publication: 8 March 2017.

Revision received: 2 June 2017.

Accepted for publication: 5 June 2017.

This work is licensed under a Creative Commons Attribution NonCommercial 4.0 License (CC BY-NC 4.0).

(C) Copyright A.L. Bogoeva et al., 2017

Licensee PAGEPress, Italy

Wine Studies 2017; 6:6695

doi:10.4081/ws.2017.6695

\section{Materials and Methods}

The grape seeds flour was delivered by a scientific institute in the town of Parvenets, Bulgaria. Briefly, the flour was produced as follows. After the alcoholic fermentation of wine, the grape seeds were extracted, then dried at atmospheric conditions and subjected to oil extraction using a screw press. Different grape varieties were blended in order to obtain sufficient amount of samples for analysis. After de-oiling phase, the grape seeds were milled to a flour. All the samples were packed in plastic bags, then thermo-sealed and stored for three months at temperature $25^{\circ} \mathrm{C}$ and relative humidity $75 \%$. The plastic bags were provided by $I l k o$ 
Tyanev - Itaplast ET company, Asenovgrad, Bulgaria. It was prepared extracts from defatted grape seed flour to analyze antioxidant activity. The analyzed sample was subjected to triple extraction with $10 \mathrm{~mL}$ $70 \%$ ethanol using a reflux condenser and a water bath at a temperature of $80{ }^{\circ} \mathrm{C}$. The mixed extracts were filtered through filter paper and vapourized till dry in a rotary vacuum evaporator. The dry extract was dissolved in the necessary volume of $70 \%$ ethanol before the analysis.

The antioxidant activity of defatted flour from post-fermentation grape seeds was determined on the basis of the following methods.

\section{DPPH assay}

Each analyzed extract $(0.15 \mathrm{~mL})$ was mixed with $2.85 \mathrm{~mL}$ freshly prepared 0.1 $\mathrm{mM}$ solution of 1,1-diphenyl-2picrylhydrazyl radical (DPPH) in methanol. The reaction was at $37^{\circ} \mathrm{C}$ in darkness and the absorbance at $517 \mathrm{~nm}$ were recorded after 15 min against methanol.

\section{ABTS assay}

ABTS radical was generated by mixing aliquot parts of $7.0 \mathrm{mM} \mathrm{2,2}$ 'azinobis (3)ethylbenzthiazoline-6-sulfonic acid (ABTS) in distilled $\mathrm{H}_{2} \mathrm{O}$ and $2.45 \mathrm{mM}$ potassium persulfate in distilled $\mathrm{H}_{2} \mathrm{O}$. The reaction was performed for $16 \mathrm{~h}$ at ambient temperature in darkness and the generated ABTS radical is stable for several days. Before analyses, $2.0 \mathrm{~mL}$ of generated ABTS.+ solution was diluted with methanol at proportions 1:30 $(\mathrm{v} / \mathrm{v})$, so the obtained final absorbance of the working solution was about $1.0 \div 1.1$ at 734 $\mathrm{nm}$. For the assay, $2.85 \mathrm{~mL}$ of this ABTS.+ solution was mixed with $0.15 \mathrm{~mL}$ of obtained extracts. After $15 \mathrm{~min}$ at $37{ }^{\circ} \mathrm{C}$ in darkness the absorbance was measured at $734 \mathrm{~nm}$ against methanol.

\section{Ferric reducing antioxidant power (FRAP) assay}

The FRAP reagent was freshly prepared before analyzes by mixing 10 parts $0.3 \mathrm{M}$ acetate buffer ( $\mathrm{pH}$ 3.6), 1 part $10 \mathrm{mM}$ 2,4,6tripyridyl-s-triazine (TPTZ, Fluka) in 40 $\mathrm{mM} \mathrm{HCl}$ (Merck) and 1 part $20 \mathrm{mM}$ $\mathrm{FeCl}_{3} \cdot 6 \mathrm{H}_{2} \mathrm{O}$ (Merck) in distilled $\mathrm{H}_{2} \mathrm{O}$. The reaction was started by mixing $3.0 \mathrm{~mL}$ FRAP reagent with $0.1 \mathrm{~mL}$ of investigated extract. Blank sample, prepared with ethanol instead of extract was developed as well. The reaction time was $10 \mathrm{~min}$ at $37{ }^{\circ} \mathrm{C}$ in darkness and the absorbance at $593 \mathrm{~nm}$ of sample against blank was recorded.

\section{Cupric reducing antioxidant capaci- ty(CUPRAC) assay}

Reaction was started by mixing $1.0 \mathrm{~mL}$ $10 \mathrm{mM} \mathrm{CuCl} 2.2 \mathrm{H}_{2} \mathrm{O}$ (Sigma) in distilled $\mathrm{H} 2 \mathrm{O}, 1.0 \mathrm{~mL} 7.5 \mathrm{mM}$ Neocuproine (Sigma) in methanol, $1.0 \mathrm{~mL} 0.1 \mathrm{M}$ ammonium acetate buffer ( $\mathrm{pH} 7.0), 0.1 \mathrm{~mL}$ of investigated extract and $1.0 \mathrm{~mL}$ distilled $\mathrm{H} 2 \mathrm{O}$. Blank sample, with ethanol instead of extract was developed as well. The reaction was carried out for $20 \mathrm{~min}$ at $50^{\circ} \mathrm{C}$ in darkness and the sample absorption at 450 nm was recorded against the blank.

The antioxidant activity defined by all of the tested methods was expressed as $\mathrm{mM}$ Trolox equivalents (TE) per g dry weight (DW) and g extract by using calibration curve, build in range of $0.05-0.5 \mathrm{mM} 6-$ hydroxy-2,5,7,8-tetramethylchroman-2-carb oxylic acid (Trolox ${ }^{\circledR}$ ) dissolved in methanol.

The microbial load of the product under study was determined at one-month intervals during the three-month storage via: Mesophilic aerobic and facultative anaerobic bacteria, according to Bulgarian State Standard (BSS) EN ISO 4833-2:2014; ${ }^{19}$ Yeasts and moulds, according to (BSS) EN ISO 21527-2:2011;20 Escherichia coli, according to ISO 16649-2:2014:21 Salmonella spp., according to (BSS) EN ISO

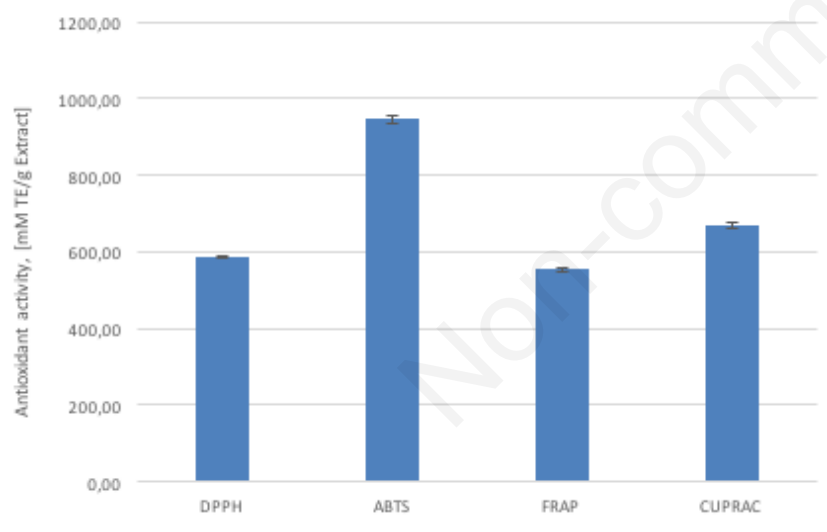

Figure 1. Antioxidant activity of defatted grape seeds flour expressed as $\mathrm{mM} \mathrm{TE} / \mathrm{g}$ extract.

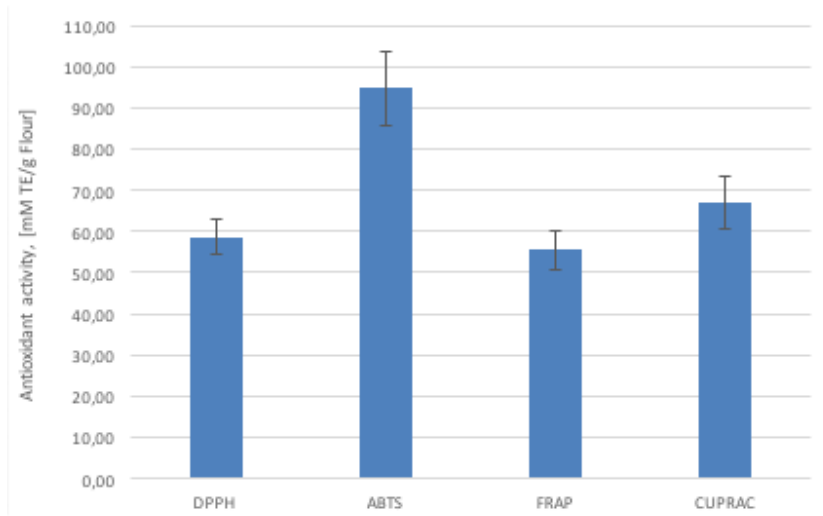

Figure 2. Antioxidant activity of defatted grape seeds flour expressed as $\mathrm{mM} \mathrm{TE} / \mathrm{g}$ flour.

Table 1. Microbiological parameters of defatted flour from post-fermentation grape seeds for three-month storage.

\begin{tabular}{|c|c|c|c|c|c|}
\hline $\begin{array}{l}\text { Sample/ } \\
\text { Day }\end{array}$ & $\begin{array}{c}\text { Total numbers of mesophilic aerobic } \\
\text { and facultative anaerobic bacteria, } \\
\text { CFU/g }\end{array}$ & $\begin{array}{c}\text { Escherichia coli, } \\
\text { CFU/g }\end{array}$ & $\begin{array}{c}\text { Staphylococcus aureus, } \\
\text { CFU/g }\end{array}$ & $\begin{array}{l}\text { Salmonella spp. / } \\
25 \mathrm{~g}\end{array}$ & $\begin{array}{l}\text { Yeasts } \\
\text { and molds, } \\
\text { CFU/g }\end{array}$ \\
\hline Day 1 & $1.5 .10^{4}$ & $<10$ & $<100$ & Not detected & $5.10^{2}$ \\
\hline Day 30 & $2.5 .10^{4}$ & $<10$ & $<100$ & Not detected & $2.10^{3}$ \\
\hline Day 60 & $3.10^{4}$ & $<10$ & $<100$ & Not detected & $2.10^{3}$ \\
\hline Day 90 & $5.10^{4}$ & $<10$ & $<100$ & Not detected & $2.10^{3}$ \\
\hline
\end{tabular}


6579:2003;22 Coagulase-positive staphylococci, according to (BSS) EN ISO 6888-1:2005.23

Flour particle size was determined with ProMel LP - 200 sieve analysis equipment. Based on preliminary analysis, the set of sieves was determined as well as their size. The sieving of the sample in the apparatus continues for ten minutes if it amounts to $100 \mathrm{~g}$.

The moisture content [\%] was determined according to AOAC 960.39. ${ }^{24}$

All tests were run in triplicate.

\section{Results and Discussion}

We obtained $100.1 \mathrm{mg}(10.01 \%)$ of extract in order to determine antioxidant activity using the methods described via extracting $1 \mathrm{~g}$ of defatted flour from postfermentation grape seeds. The antioxidant activity of the extract was determined using four methods differing in mechanism and development conditions (DPPH, ABTS, FRAP and CUPRAC). DPPH and ABTS methods are based on the transfer of a single electron (SET method) and/or the transfer of a hydrogen atom (HAT method), whereas FRAP and CUPRAC methods are based solely on single electron transfer. The results (mean value \pm standard deviation) are presented as $\mathrm{mM} \mathrm{TE} / \mathrm{g}$ extract in Figure 1 and $\mathrm{mM}$ TE/g flour in Figure 2.

The results obtained via all four methods demonstrate that defatted post-fermentation grape seeds flour shows antioxidant activity. The flour analyzed is characterized by a much greater antioxidant activity as compared to that reported by other authors. Using the DPPH method, ${ }^{2}$ determined the antioxidant activity of $70 \%$ ethanol extract of grape seeds flour from different grape varieties (Chardonnay, Concord, Norton, Ruby Red, White) as varying between 0.5 $7.0 \mathrm{mM} \mathrm{TE} / \mathrm{g}$ flour. Lutterodt et al. ${ }^{10}$ also arrived at a considerably lower antioxidant activity, as compared to the DPPH method, of various grape seeds flours (for the grape cultivars Muscadine, Concord, Ruby Red, Chardonnay, and Soybean), the values amounting to $11.8-15.0 \mathrm{mM} \mathrm{TE} / \mathrm{g}$ flour. According to Kim et al., ${ }^{18}$ antioxidant content depends to a large extent on the treatment of grape seeds during thermal processing.

Regarding the antioxidant activity of defatted flour from post-fermentation grape seeds, the differences between the data in the present study and that of other authors ${ }^{2,10,18}$ are attributable to the specificities of grape varieties, climatic conditions, and technological processes used in flour production.

During the three-month storage of the grape seeds flour at a temperature of $25^{\circ} \mathrm{C}$ and relative air humidity of $75 \%$, we studied the microbiological parameters having to do with E. coli, Salmonella spp., coagulasepositive staphylococci, total amount of mesophilic aerobic and facultative anaerobic bacteria, yeasts and moulds, granulometric composition, and flour moisture (Table 1).

Storage conditions. Relative air humidity and temperature were selected in accordance with the storage conditions of the product in warehouses and markets.

Table 1 shows the results from the microbiological parameters analyzed for the whole period of storage.

The parameters Total numbers of mesophilic aerobic and facultative anaerobic bacteria and Yeasts and molds remain from Day 1 to Day 90 of storage. The higher microbial load concerning these two parameters, still below the threshold limits,

Table 2. Granulometric composition of post-fermentation grape seeds flour during threemonth storage.

\begin{tabular}{llccc} 
& Particles size, m & \multicolumn{3}{c}{ Quantity of break stock, \% } \\
1 month & 3 months \\
\hline 1 & 670 & 4.3 & 9.2 & 10.1 \\
\hline 2 & 560 & 8.9 & 7.3 & 8.7 \\
\hline 3 & 450 & 14.3 & 13.1 & 15.4 \\
4 & 355 & 40.1 & 43.3 & 40.6 \\
\hline 5 & 280 & 0.3 & 3.1 & 2.4 \\
6 & 200 & 3.1 & 15.9 & 15.1 \\
\hline 7 & 180 & 4.2 & 2.3 & 2.0 \\
8 & 150 & 13.1 & 2.3 & 2.9 \\
\hline 9 & 132 & 2.1 & 1.6 & 1.1 \\
10 & less than 132 & 9.6 & 1.9 & 1.7 \\
\hline 11 & Flour moisture content, $\%$ & 9.65 & 10.45 & 7.85 \\
\hline
\end{tabular}

\section{Conclusions}

The analyzed $70 \%$ ethanol extract of post-fermentation grape seeds flour demonstrated a relatively high antioxidant activity as assessed through the capacity to interact with free radicals (DPPH and ABTS methods) as well as the capacity to reduce iron and copper ions (FRAP and CUPRAC methods).

During the three-month storage of the grape seeds flour in a plastic bags (at temperature $25{ }^{\circ} \mathrm{C}$ and relative humidity $75 \%$ ), no living cells of pathogenic organisms or apparent molding were detected. The flour particles size was not changed considerably.

\section{References}

1. Kris-Etherton PM, Hecker KD, Bonanome A, et al. Bioactive 
compounds in foods: their role in the prevention of cardiovascular disease and cancer. Am J Med 2002;113:71S-88S.

2. Binzer L, Brinsko R, Cha J, et al. Incorporating grape seeds antioxidants into a functional food model. University of Maryland, College Park, 2011.

3. Balga I, Kiss A, Gál L, et al. Evaluating the correlation between chemical and sensory compounds in Blaufränkisch and Cabernet Franc wines. Wine Studies 2014;3:16-18.

4. Georgiev V, Ananga A, Tsolova V. Recent advances and uses of grape flavonoids as nutraceuticals. Nutrients 2014;6:391-415.

5. Jayaprakasha GK, Singh RP, Sakariah KK. Antioxidant activity of grape seed (Vitis vinifera) extracts on peroxidation models in vitro. Food Chem 73;2001:285-90.

6. Dai J, Mumper RJ. Plant phenolics: Extraction, analysis and their antioxidant and anticancer properties. Molecules 2010;15:7313-52.

7. Henning B, Ettinger AS, Jandacek RJ, et al. Using nutrition for intervention and prevention against environmental chemical toxicity and associated diseases. Environ Health Perspect 2007;115:493-5.

8. Rockenbach II, Rodrigues E, Gonzaga $\mathrm{LV}$, et al. Phenolic compounds content and antioxidant activity in pomace from selected red grapes (Vitis vinifera L. and Vitis labrusca L.) widely produced in Brazil. Food Chem 2011;127:174-9.

9. Bhise S, Kaur A, Gandhi N, Gupta R. Antioxidant property and health benefits of grape byproducts. J Postharvest Technol 2014;2:1-11.
10. Lutterodt H, Slavin M, Whent M, et al. Fatty acid composition, oxidative stability, antioxidant and antiproliferative properties of selected cold-pressed grape seeds oils and flours. Food Chem 2011;128:391-9.

11. Nowshehri JA, Bhat ZA, Shah MY. Blessings in disguise: Bio-functional benefits of grape seeds extracts. Food Res Int 2015;77:333-48.

12. Munteanu MF, Gligor R, Alexa E, et al. Determination of the nutritional properties from grape seeds flour. Poster presentations. Current Opinion Biotechnol 2013;24S:S48-S143.

13. Yamakoshi J, Saito M, Kataoka S, Kikuchi M. Safety evaluation of proanthocyanidin-rich extract from grape seeds. Food Chem Toxicol 2002;40:599-607.

14. Kulkarni S, DeSantos FA, Kattamuri S, et al. Effect of grape seeds extract on oxidative, color and sensory stability of a pre-cooked, frozen, re-heated beef sausage model system. Meat Sci 2011;88:139-44.

15. Ozvural EB, Varal H. Grape seeds flour is a viable ingredient to improve the nutritional profile and reduce lipid oxidation of frankfurters. Meat Sci 2011;88:179-83.

16. Sant'Anna V, Dalla Porta Christiano F, Damasceno Ferreira Marczak L, Tessaro IC, Cruz Silveira Thys R. The effect of incorporation of grape marc powder in fettuccini pasta properties. LWT - Food Sci Technol 2014;58:497-501.

17. Green PHR, Jabri B. Coeliac disease. Lancet 2003;362,383-91.

18. Kim SY, Jeong SM, Park WP, et al. Effect of heating conditions of grape seeds on the antioxidant activity of grape seeds extracts. Food Chem 2006;97:4729.

19. (BSS) EN ISO 4833-2. Microbiology of food chain - Horizontal method for the enumeration of microorganisms - colony count at $30^{\circ} \mathrm{C}$ by the surface plating thechnique. Bulgarian State Standard; 2014.

20. (BSS) EN ISO 21527-2. Microbiology of food and animal feeding stuffs Horizontal method for the determination of yeasts and moulds. Bulgarian State Standard; 2011.

21. (BSS) EN ISO 16649-2. Microbiology of food and animal feeding stuffs Horizontal method for the enumeration of beta-glucuronidase-positive Escherichia coli - colony count technique at 44 degrees $\mathrm{C}$ using 5bromo-4-chloro-3-indolyl beta-D-glucuronide. Bulgarian State Standard (BSS); 2014.

22. (BSS) EN ISO 6579. Microbiology of food and animal feeding stuffs Horizontal method for the detection of Salmonella spp. Bulgarian State Standard; 2003.

23. (BSS) EN ISO 6888-1. Microbiology of food and animal feeding stuffs Horizontal method for the enumeration of coagulase-positive staphylococci (Staphylococcus aureus and other species). Bulgarian State Standard; 2005.

24. AOAC, Official Methods of Analysis, 15 th ed. Association of Official Analytical Chemists, Washington DC. 1990. 